\title{
Degree of conversion of a flowable composite light-activated through ceramics of different shades and thicknesses
}

\author{
Adilson Yoshio Furuse ${ }^{1}$, Daniel Hatschbach Glir $^{2}$, Fabio Antonio Piola Rizzante ${ }^{1}$, Rayane Prochnow ${ }^{2}$, \\ Ana Flávia Sanches Borges ${ }^{1}$, Carla Castiglia Gonzaga ${ }^{2}$
}

${ }^{1}$ Universidade de São Paulo - USP, School of Dentistry of Bauru, Department of Operative Dentistry, Endodontics and Dental Materials, Bauru, SP, Brazil ¿Universidade Positivo - UP, School of Dentistry, Graduate Program in Dentistry, Curitiba, PR, Brazil

\begin{abstract}
The cementation of thin ceramic veneers employing fluid light-activated resin-based materials is a common procedure in the dental practice. Aim: To evaluate the influence of ceramic thickness and shade on the degree of conversion (DC) of a flowable light-activated material. Methods: flowable resin composite (Tetric N-Flow - shade A1) was light-activated through ceramic discs of two shades (IPS Classic - A1 and A3) in three thicknesses $(0.5,0.7$ and $1.0 \mathrm{~mm})$. For control, the resin composite was light-activated without ceramic interposition. DC was evaluated by FTIR $(n=5)$. Data were analyzed by one-way ANOVA and Dunnett's T3 test $(\alpha=0.05)$. Results: Statistically significant differences between groups were observed $(p<0.001)$. Control group (without the interposition of ceramic) showed the highest mean for $D C(71.9 \pm 1.7)$. Considering the interposed ceramic disc groups, the highest DC values were obtained when 0.5 and $0.7 \mathrm{~mm}$ A1 ceramics were used (64.6 \pm 1.2 and 64.45 .0 , respectively) and the lowest DC values were obtained for 0.7 and $1 \mathrm{~mm}$ A3 ceramics (61.74 \pm 0.9 and $62.0 \pm 1.9$, respectively). Conclusions: No flowable resin composite group with interposing ceramics reached a DC similar to the control group.
\end{abstract}

Keywords: composite resins; polymerization; dental materials; ceramics.

\section{Introduction}

Dental ceramics have become well known due their great esthetic quality, capacity of mimicking the dental structure, high wear and staining resistances, color stability and biocompatibility ${ }^{1}$. Conversely, it is well established that ceramic

Received for publication: August 31, 2015 Accepted: September 26, 2015

Correspondence to: Adilson Yoshio Furuse Departamento de Dentística, Endodontia e Materiais Odontológicos

Faculdade de Odontologia de Bauru, Universidade de São Paulo - USP

Alameda Dr. Octávio Pinheiro Brisolla, 9-75 CEP: 17012-901 Bauru, SP, Brasil Phone: +55 14 3235-8253 E-mail: furuse@usp.br veneers should be firmly fixed to dental structure in order to achieve better clinical longevity. Thus, despite the superior physical-chemical properties of ceramic materials when compared to other dental esthetic restorative materials, such as resin composites, the clinical success of ceramic restorations depends on the properties of the cementation material as well as the cementation technique ${ }^{2}$.

Luting materials are considered clinically acceptable if they present appropriate resistance to solubilization, high adhesion to dental substrates, high strength under tension, good manipulative properties, and biocompatibility in the oral environment and to the dental tissues ${ }^{2-3}$. In order to improve these properties, the material should be properly polymerized. Thus, one of the most important aspects related to the characteristics of resin-based materials is the 
polymerization level or degree of conversion (DC) of monomer chains into polymers ${ }^{4-5}$. DC is important because properties such as strength, color stability and biocompatibility are closely related to $i^{6-8}$. The biocompatibility is related to the concept that unreacted monomers have cytotoxic potential in contact with biological tissues ${ }^{9}$. Thus, since the physical/chemical properties of resin-based cements are related to how the polymerization occurs, it is important to study and understand the factors that may influence the DC, such as thickness and color of the ceramic material interposed between the light source and the resin cement.

In the case of the cementation of ceramic veneers, the use of light-activated resin-based materials has increased due to the working time control ${ }^{10}$. This clinical advantage, however, should not be the determinant factor for material choice in veneer cementation due to the possible attenuating effect provided by thickness, opacity and shades ${ }^{11-13}$. Additionally, the type and microstructure of the interposing ceramic material are significant factors in the properties of polymerized luting materials ${ }^{14}$. In general, the use of these light-activated cements should be limited to some clinical situations such as inlays, veneers and onlays, in which the thickness and shade of restoration do not affect the ability of light to reach and activate the cement ${ }^{15}$.

Considering the light-activated resin cements for veneers and onlays cementation, the polymerization quality is related to several factors such as photo-activation light source, irradiance, irradiation time, material composition and light attenuation caused by ceramic $c^{11,13-14,16-18}$. It was observed that the transmittance of light through ceramic decreases as function of the material interposed between the light source and the resin cement ${ }^{19}$.

Furthermore, for a single ceramic material with different shades and thickness, it can be hypothesized that the polymerization may vary due to differences in the transmission of photons through the ceramic. Therefore, the clinical performance would be determined by the amount of light transmitted through the restoration that reaches the resinbased cement. Thus, the aim of this study was to evaluate the influence of ceramic color and thickness on the DC of a flowable light-activated resin composite. The working hypothesis was that the shade and thickness of interposing ceramic material influence DC.

\section{Material and methods}

The materials used in this research are in Table 1. Feldspathic ceramic discs (IPS Classic, Ivoclar Vivadent,
Schaan, Liechtenstein) $12 \mathrm{~mm}$ diameter and 0.5, 0.7 and 1.0 $\mathrm{mm}$ thickness were prepared with the shades A1 and A3. All spacers were fabricated according to the manufacturer's instructions. The thickness was measured by a digital caliper (Starret, Jiangsu, China) with $0.01 \mathrm{~mm}$ accuracy.

For DC evaluation, a portion of approximately $0.05 \mathrm{~g}$ of the uncured shade A1 Tetric N-Flow (Ivoclar Vivadent, Schaan, Liechtenstein) flowable resin composite was dispensed onto a plastic film. Another plastic film was placed over the material and the set was pressed with a pneumatic press (Shimadzu, Kyoto, Japan) at $10 \mathrm{kN}$ to obtain a thin film approximately $0.1 \mathrm{~mm}$ thick and $20.0 \mathrm{~mm}$ diameter $(\mathrm{n}=5)$. These composite films were light-activated through different interposed ceramic spacers with a $1200 \mathrm{~mW} / \mathrm{cm}^{2}$ LED curing light (Radii-Cal, SDI Limited, Bayswater, Australia) for $45 \mathrm{~s}$. The light intensity was determined before the beginning of the experiments by a radiometer (Demetron, Kerr, Middleton, WI, USA) without the interposition of ceramic disks.

The samples were subjected to Fourier transformed infrared spectroscopy (FTIR) with a resolution of $4 \mathrm{~cm}^{-1}$ and 32 scans ranging from 4,000 to $800 \mathrm{~cm}^{-1}$. The absorption peaks of aromatic double bonds at $1608 \mathrm{~cm}^{-1}$ (Abs 1608) and aliphatic double bonds at $1636 \mathrm{~cm}^{-1}$ (Abs 1636) were recorded before and after the light-activation. Five measurements were performed for each condition.

The ratio between Abs 1636 and Abs 1608 was calculated for both cured and uncured materials. The percentage of remaining double bonds (RDB) was determined according to the formula:

$\% \mathrm{RDB}=($ Abs 1636/Abs 1608 for cured resin $) \times 100 /$ (1636 Abs/Abs 1608 for uncured resin)

The percentage of the degree of conversion of double bonds (DC) was calculated by the following formula:

$\% \mathrm{DC}=100-\% \mathrm{RDB}$

Data were submitted to one-way ANOVA. Multiple comparisons were performed using the Dunnett's T3 test. A global level of 0.05 significance was set.

\section{Results}

The DC mean values and standard deviations for the flowable resin light-activated through ceramic of different shades and thicknesses are shown in Table 2. Statistically significant differences were observed between groups $(p<0.001)$. The control group (without interposition of ceramic) showed the highest mean percentage of DC (71.9 \pm 1.7$)$. The lowest DC values were obtained for the 0.7

Table 1 - Materials used in the study.

\begin{tabular}{|c|c|c|}
\hline Material & Type & Composition \\
\hline Tetric N-Flow & Flowable resin composite & $\begin{array}{l}36 \text { wt.\% dimethacrylate (including TEGDMA), } 63 \text { wt.\% fillers (barium glass, ytterbium trifluoride, highly } \\
\text { dispersed silica and mixed oxide) and } 1 \text { wt.\% catalysts, stabilizers and pigments. The total content of } \\
\text { inorganic fillers is } 39 \text { vol.\%. The particle size of inorganic fillers is between } 40 \text { and } 3000 \mathrm{~nm}\end{array}$ \\
\hline IPS Classic & Feldspathic ceramic & $\begin{array}{l}\mathrm{SiO}_{2}, \mathrm{BaO}, \mathrm{Al}_{2} \mathrm{O}_{3}, \mathrm{CaO}, \mathrm{CeO}_{2}, \mathrm{Na}_{2} \mathrm{O}, \mathrm{K}_{2} \mathrm{O}, \mathrm{B}_{2} \mathrm{O}_{3}, \mathrm{MgO}, \mathrm{ZrO}_{2}, \mathrm{P}_{2} \mathrm{O}_{5}, \mathrm{TiO}_{2} \text {, and pigments (composition } \\
\text { according to the Material Safety Data Sheet) }\end{array}$ \\
\hline
\end{tabular}


Table 2 - Mean values and standard deviations for DC. Different superscript letters represent statistically significant differences $(\mathrm{p}<0.05)$.

\begin{tabular}{lll}
\hline Ceramic shade & Thickness (mm) & DC* (in \%) \\
& $\begin{array}{l}\text { Control (without ceramic } \\
\text { interposition) }\end{array}$ & $71.9 \pm 1.7^{\mathrm{a}}$ \\
\hline A1 & 0.5 & $64.6 \pm 1.2^{\mathrm{b}}$ \\
& 0.7 & $64.4 \pm 5.0^{\mathrm{bc}}$ \\
& 1.0 & $62.7 \pm 4.7^{\mathrm{bc}}$ \\
\hline A3 & 0.5 & $62.7 \pm 1.4^{\mathrm{bc}}$ \\
& 0.7 & $61.7 \pm 0.9^{\mathrm{c}}$ \\
& 1.0 & $62.0 \pm 1.9^{\mathrm{c}}$ \\
\hline
\end{tabular}

${ }^{*} \mathrm{DC}$ degree of conversion

and $1 \mathrm{~mm}$ A3 ceramics $(61.7 \pm 0.9$ and $62.0 \pm 1.9$, respectively).

\section{Discussion}

This study confirmed the hypothesis that the shade and thickness of interposing ceramic material would influence the DC. Although no flowable resin composite group with interposing ceramics reached DC similar to the control group, little difference in the DC was observed when ceramics of different thicknesses and shades were compared. Possible explanations for this result are the high irradiance of the LED curing light used in this study, the reduced thickness of the ceramic veneers (up to $1 \mathrm{~mm}$ ) and the thin films of flowable resin composite used to determine the DC. Thus, the possible attenuating effect of light by ceramic interposition was not sufficient to negatively affect DC.

It should be noted that only one feldspathic ceramic was evaluated in the present study. Ceramic systems with different levels of opacity are commercially available, and DC results could be different if ceramics presenting other opacities and microstructures were evaluated. More opaque ceramics tend to absorb more light, which would decrease the DC of light-cured resin-based materials ${ }^{20}$. It has been reported that the DC of resin-based materials may change considerably as function of the type and opacity of the interposing ceramics ${ }^{13-14}$.

Another aspect to be addressed is that one single shade of flowable resin composite was evaluated. As recently observed, the shade is an important factor for the development of mechanical properties of resin-based cements. Darker shades may show inferior properties than the lighter ones ${ }^{21}$. Thus, the results of the present study could be different if other shades of resin composite (i.e. darker or bleached teeth) were evaluated. Additionally, the composition and irradiation time are important factors that influence DC of resin composites $^{22-23}$. It should be noted that, according to the manufacturer, Tetric N-Flow is a radiopaque nano-hybrid light-activated flowable resin composite indicated for adhesive cementation of translucent ceramic and composite resin indirect restorations. Although the resin composite evaluated in the present study is indicated for the cementation of ceramic restorations, other light-activated materials (i.e. the so called "veneer cements") have been indicated for the cementation of thin veneers ${ }^{10}$ and also have shown good DC results when light-activated through ceramic materials ${ }^{13-14}$.

As seen in Table 2, the similar results for DC in most groups indicate that the shade and thickness of the evaluated interposed ceramic veneers did not influence the polymerization of the flowable resin composite. This result shows that a lightactivated flowable resin may be used to fix minimum thickness ceramic veneers without a great effect on the DC level. This result is in agreement with another study that used the same method of the present study, in which the DC was not affected when 1.5 -mm-thick ceramics were interposed ${ }^{13}$. Similar results were also observed by Cho et al. ${ }^{11}$ (2015).

Other important factors to be considered are the exposure time and interposed ceramic opacity. Archegas et al. ${ }^{20}$ (2011) observed that opaque ceramic resulted in lower degree of conversion, hardness and elasticity modulus of resin-based cements. An exposure time of $120 \mathrm{~s}$ produced higher degree of conversion values for all materials, regardless the opacity of the ceramic. Moreover, the exposure of $120 \mathrm{~s}$ promoted higher hardness and modulus of elasticity values than those obtained when the cements were light-activated for $40 \mathrm{~s}$. Thus, the results of the present study could be different if longer light-activation times were used. It should be noted that, although the manufacturer of the resin composite evaluated in the present study recommends a 10-s lightactivation time when a curing device with irradiance higher than $1000 \mathrm{~mW} / \mathrm{cm}^{2}$ is used, a $45-\mathrm{s}$ light-activation time was used instead. This increased irradiance $\left(1200 \mathrm{~mW} / \mathrm{cm}^{2}\right)$ and light-activation time $(45 \mathrm{~s})$ could have reduced the attenuation of light caused by the evaluated ceramics.

Besides the DC, it should be noted that the clinical longevity of all-ceramic restorations includes other factors, such as the used adhesive system, the mechanism of polymerization, the polymerization unit, and the microstructural characteristics and thickness of the ceramic material ${ }^{24}$. For this reason, other studies should be conducted addressing the long-term behavior of light-activated resin cements cured through ceramics when different protocols of adhesive system application are employed.

There was no statistically significant difference between the evaluated thickness and shades, except when comparing $0.5 \mathrm{~mm} \mathrm{~A} 1$ and $1.0 \mathrm{~mm} \mathrm{~A} 3$ ceramics. These results indicate that this flowable resin may be used to cement minimum thickness laminate ceramic veneers without great impact on the conversion degree. Nevertheless, no flowable resin composite group with interposing ceramics reached a DC similar to the control group. It may be concluded that the shade and thickness of interposing glass-ceramic did not influence the DC of a flowable resin composite when ceramic was interposed.

\section{Acknowledgements}

This study was supported by the PIBIC/CNPq. The authors also acknowledge the manufacturer for providing the resin composite. 


\section{References}

1. Lawson NC, Burgess JO. Dental ceramics: a current review. Compend Contin Educ Dent. 2014; 35: 161-6.

2. Manso AP, Silva NR, Bonfante EA, Pegoraro TA, Dias RA, Carvalho RM. Cements and adhesives for all-ceramic restorations. Dent Clin North Am. 2011; 55: 311-32.

3. Rosenstiel SF, Land MF, Crispin BJ. Dental luting agents: A review of the current literature. J Prosthet Dent. 1998; 80: 280-301.

4. Watts DC. Reaction kinetics and mechanics in photo-polymerised networks. Dent Mater. 2005; 21: 27-35.

5. Furuse AY, Mondelli J, Watts DC. Network structures of Bis-GMA/ TEGDMA resins differ in DC, shrinkage-strain, hardness and optical properties as a function of reducing agent. Dent Mater. 2011; 27: 497-506.

6. Atsumi T, Iwakura I, Fujisawa S, Ueha T. The production of reactive oxygen species by irradiated camphorquinone-related photosensitizers and their effect on cytotoxicity. Arch Oral Biol. 2001; 46: 391-401.

7. Lapp CA, Schuster GS. Effects of DMAEMA and 4-methoxyphenol on gingival fibroblast growth, metabolism, and response to interleukin-1. J Biomed Mater Res. 2002; 60: 30-5.

8. Peutzfeldt $A$, Asmussen $E$. The effect of postcuring on quantity of remaining double bonds, mechanical properties, and in vitro wear of two resin composites. J Dent. 2000; 28: 447-52.

9. dos Santos RL, de Sampaio GA, de Carvalho FG, Pithon MM, Guenes $\mathrm{GM}$, Alves PM. Influence of degree of conversion on the biocompatibility of different composites in vivo. J Adhes Dent. 2014; 16: 15-20.

10. da Cunha LF, Pedroche LO, Gonzaga CC, Furuse AY. Esthetic, occlusal, and periodontal rehabilitation of anterior teeth with minimum thickness porcelain laminate veneers. J Prosthet Dent. 2014; 112: 1315-8.

11. Cho SH, Lopez A, Berzins DW, Prasad S, Ahn KW. Effect of Different Thicknesses of Pressable Ceramic Veneers on Polymerization of Light-cured and Dual-cured Resin Cements. J Contemp Dent Pract. 2015; 16: 347-52.

12. Peixoto RT, Paulinelli VM, Sander HH, Lanza MD, Cury LA, Poletto LT. Light transmission through porcelain. Dent Mater. 2007; 23: 1363-8.

13. Runnacles P, Correr GM, Baratto Filho F, Gonzaga CC, Furuse AY. Degree of conversion of a resin cement light-cured through ceramic veneers of different thicknesses and types. Braz Dent J. 2014; 25: 38-42.

14. Calgaro PA, Furuse AY, Correr GM, Ornaghi BP, Gonzaga CC. Influence of the interposition of ceramic spacers on the degree of conversion and the hardness of resin cements. Braz Oral Res. 2013; 27: 403-9.

15. Caughman WF, Chan DC, Rueggeberg FA. Curing potential of dualpolymerizable resin cements in simulated clinical situations. J Prosthet Dent. 2001; 86: 101-6.

16. Ilie N, Hickel R. Correlation between ceramics translucency and polymerization efficiency through ceramics. Dent Mater. 2008; 24: 908-14.

17. Lohbauer U, Pelka M, Belli R, Schmitt J, Mocker E, Jandt KD, et al. Degree of conversion of luting resins around ceramic inlays in natural deep cavities: a micro-Raman spectroscopy analysis. Oper Dent. 2010; 35: 579-86.

18. Ozturk B, Cobanoglu N, Cetin AR, Gunduz B. Conversion degrees of resin composites using different light sources. Eur J Dent. 2013; 7: 102-9.

19. Pick B, Gonzaga CC, Junior WS, Kawano Y, Braga RR, Cardoso PE. Influence of curing light attenuation caused by aesthetic indirect restorative materials on resin cement polymerization. Eur J Dent. 2010; 4: 314-23.

20. Archegas LR, Freire A, Vieira S, Caldas DB, Souza EM. Colour stability and opacity of resin cements and flowable composites for ceramic veneer luting after accelerated ageing. J Dent. 2011; 39: 804-10.

21. Ozturk E, Bolay S, Hickel R, llie N. Effects of ceramic shade and thickness on the micro-mechanical properties of a light-cured resin cement in different shades. Acta Odontol Scand. 2015; 73: 503-7.

22. Cornelio RB, Kopperud HM, Haasum J, Gedde UW, Örtengren U. Influence of different mould materials on the degree of conversion of dental composite resins. Braz J Oral Sci. 2012; 11: 469-74.
23. Catelan A, Kawano Y, Santos PH, Ambrosano GMB, Berdran-Russo AK, Aguiar FHB. Radiant exposure effects on physical properties of methacrylate - and silorane-composites. Braz J Oral Sci. 2014; 13: 168-74.

24. Rasetto FH, Driscoll CF, Prestipino V, Masri R, von Fraunhofer JA. Light transmission through all-ceramic dental materials: a pilot study. J Prosthet Dent. 2004; 91: 441-6. 